\title{
Taboos and Desires of the UK Public for Identity Management in the Future - Findings from Two Survey Games
}

\author{
Liesbet van Zoonen \\ Loughborough University \\ Leicestershire UK, LE11 3TU \\ e.a.van-zoonen@lboro.ac.uk
}

\author{
Georgina Turner \\ Loughborough University \\ Leicestershire UK, LE11 3TU \\ g.turner@ Iboro.ac.uk
}

\begin{abstract}
In this paper, we analyze user experiences and expectations about the future of identification and authentication (I\&A). We focus on structural taboos and desires around I\&A and try to tap into fundamental concerns that may be relevant across particular technologies or contexts. We collected data by running two gamified surveys in which a representative sample of the UK public $(\mathrm{N}=1000)$ were engaged in $\mathrm{I} \& \mathrm{~A}$ narratives that were accompanied by a colorful design, visuals and audio effects. We found that people use a traditional set of I\&A instruments, i.e. passport, driving license, bank card, pincodes and passwords. Few of them are heavy users of biometrics. People experience little problems with their current means of I\&A and do not like the kind of futuristic means of I\&A that are presented in popular culture, arts and design, and some R\&D departments of big corporations. If people see room for improvements of their future means of I\&A, they tend to desire higher ease and transparency of the cards they use. People hope and expect I\&A in the future to become even more personalized; they hope to get more control over their online identities but there is widespread doubt this will become possible; they fear and expect commercialization of I\&A services, and expect that surveillance will expand (about which they have mixed feelings). We end the paper with recommendations for further research and for designers of I\&A systems.
\end{abstract}

\section{Categories and Subject Descriptors}

J.4. [Social and Behavioral Sciences]; J.5. [Sciences - sociology]; K.4. [Computers and Society]; K.4.1. [Public Policy Issues] Privacy; K.6.5. [Security and Protection] Authentication

\section{Keywords}

Identity Management; Identification; Authentication; Diffusion of Innovation; Technology Acceptance; Gamification; RFID; Biometrics; Smart Tokens; Passwords; Pincodes; Cultural Frames.

Permission to make digital or hard copies of part or all of this work for personal or classroom use is granted without fee provided that copies are not made or distributed for profit or commercial advantage and that copies bear this notice and the full citation on the first page. Copyrights for third-party components of this work must be honored. For all other uses, contact the Owner/Author.

Copyright is held by the owner/author(s).

$D I M^{\prime} 13$, November 8, 2013, Berlin, Germany.

ACM 978-1-4503-2493-9/13/11.

http://dx.doi.org/10.1145/2517881.2517887

\section{INTRODUCTION}

In current societies, there are ever more contexts in which you have to identify or authenticate (I\&A) yourself. No longer are governments the only institutions asking for I\&A; in corporate, leisure, education, public transport and online environments I\&A have become a prerequisite for actions and transactions. As a result, it will become ever more difficult to lead our everyday lives without an acceptable form of I\&A. Both governments and industry are working hard to develop identity management systems that are easy to use, efficient and secure. As common in the development of new technologies real-life users are often not part of the process; developers tend to take themselves as measure of acceptability or usability (as, e.g., the phrase "I-technology" aptly captures [1]) or they tend to assume a user that is a mostly rational actor weighing pros and cons in making a cognitive decision (as in many studies of technology acceptance [2]). Usability studies of online systems often suffer from validity problems that follow from laboratory testing, small sample size and biased user selection [3]. Nevertheless, it is crucial to include user expectations and experiences into the development of future systems of identity management.

In the research we present here, we have tried to delve into user experiences and expectations for the future, by exploring structural taboos and desires around identity management, and tapping into fundamental concerns that may be relevant across particular technologies or I\&A contexts. Given that many of the new technologies are still in the future, we have also tried to employ a method that would invite a 'future' mindset among our respondents. We thus conducted two surveys in the form of game play, so called ResearchGames, among a representative sample of the UK public ( $\mathrm{N}=1000$, data collection spring 2013).

\section{RESEARCH QUESTIONS}

We focused our research on taboos and desires for future technologies of I\&A, potential new functionalities and possible models of governance. We constructed the questions and stimuli for these from an extensive scenario analysis about IM in the future as envisaged in government policies, popular culture, arts and design, corporate research and development, journalism, civic activism and academic research. For each of these sectors we identified the main predictions for the future through thematic and discursive analyses, and summarized them into a typology combining three types of I\&A (memory, token and body-based) and three interaction contexts in which I\&A is necessary (interactions with organisations, with 'things' and with other people) [4]. 


\subsection{I\&A technologies}

In future scenarios, the memory based technologies (passwords and pincodes) tend to be seen as insecure and user-unfriendly, and therefore in need of replacement by safer and easier technologies. In addition, there is general concern about card theft and card fraud. Biometrics and sometimes RFID implants or pills have been presented as possible body based alternatives, while smart jewelry and textiles would offer token-based alternatives. We therefore ask three types of questions, regarding:

- Usage of, and problems with current means of I\&A

- Expectations of future developments around particular means of I\&A

- $\quad$ Liking and expecting to use smart jewelry, smart tattoos or implants

\subsection{I\&A functionalities}

In the future scenarios we came across different options for enhanced functionalities of existing means I\&A, which would counter current problems and deficiencies. An existing but little used possibility, for instance, concerns the online password service which stores all your passwords and inserts them when and where necessary. Such a 'one-fits-all' option has also been discussed in the context of customer loyalty cards, with one card offering access to a plethora of commercial services and benefits. In addition, following the popularity of social media, the possibilities of I\&A to connect to other people is also a popular option in all kinds of future scenarios, especially when connected to the smart phone. We therefore ask two types of questions:

Regarding improved functionalities of I\&A cards

- Regarding the replacement of cards by smart phone apps or body based instruments

\subsection{I\&A governance}

Finally, a big part of future scenarios concerns issues of privacy, data storage and safety, and accountability. These are also a crucial part of public debate and policy development around I\&A, and a failure to provide satisfactory solutions to citizens has resulted in some considerable I\&A disasters (with, e.g. the UK ID card, or the Dutch electronic patient file). Paradoxically, there is much less discussion about the accountability of corporate I\&A and in a consumption context people seem to be less concerned about giving up their data in exchange for particular services. In this context we compare the desirability of five particular models of governance that were found in the scenario analysis:

- $\quad$ Surveillance futures (dominant scenario in pop culture)

- Accountable and responsible government (dominant scenario in government policy)

- User centric approaches (important scenario among user groups)

- $\quad$ Transparency and reciprocity (important scenario among some advocacy groups)

- Commercialized privacy (important scenario in the corporate sector)

\subsection{Individual differences}

In addition to analyzing the quantitative distribution of taboos and desires for new I\&A technologies, functionalities and modes of governance, we are interested in whether they are connected to particular kinds of people. Existing research about the acceptance of new technologies or new products suggest that differences among people emerge from variable combinations of sociodemographic variables, media use patterns and value differences [5].

\section{DESIGN, DATA COLLECTION, AND ANALYSIS}

In order to get an overall picture of the UK public, we decided for a survey-based form of data collection, which would deliver a representative picture of the distribution of taboos and desires, in connection with individual differences based on socio-demographic features, media use patterns and cultural values. The representative sample for our survey was recruited by a specialized agency. We also decided to collect the data online. Admittedly, there are bias issues with collecting data online, but on the other hand almost $85 \%$ of the UK is online, and we also wanted to ask questions about online identification.

A more problematic issue concerns survey fatigue: survey response rates continue to decline (and in the case of web surveys, were never as high as with other formats) as people are asked to complete more and more surveys, so their interest in them continues to wilt. This can manifest itself in several ways that researchers would rather avoid, such as "straight-lining" (choosing the same response to a string of questions that use the same scale), choosing random answers to speed up the survey, and not bothering to finish the survey. To prevent such problems we created two gamified surveys: one aimed at assessing how people manage their identities now, and one geared to what they desire (or not) for the future. The two ResearchGames, as they are called, were designed in collaboration with a specialized London-based agency, ResearchThrough-Gaming (www.researchthroughgaming.com), and involved drawing the respondents into game-like narratives about I\&A now and in the future, combined with attractive design, visuals and sound. By answering questions and clicking on visual icons they could reach the next level of the game until they had answered all questions and finished the game, for which they then received an online award icon.

The narrative in the first game, TESSA, places the respondent in the fictional situation of being a spy trying to identify, track and capture an undercover agent. The game was aimed at providing benchmark data about people's current means of I\&A and the problems they experience with them. It also presented visuals of futuristic means of I\&A to which people could respond (go to www.imprintsfutures.org, to play the game). The second game, DUBIOUS, suggests the respondents that they live in 2030 and all of a sudden wake up in 2013. They have to convince a friend, a colleague and their GP that they are really from the future by answering their questions about how I\&A is organized and governed in the future. This game also involves the construction of an avatar who has all kinds of futuristic means of I\&A at her/his disposal. Obviously this gamified method is different than usual, and evokes all kinds of questions around validity and reliability. Our reflections on the methodological challenges of Research Games did not produce compelling reasons to doubt the 
quality of the data; in fact, over $90 \%$ of the respondents said they had enjoyed this new form of data collection and expressed willingness to play more of such games [6].

The questionnaire underlying the two ResearchGames was constructed on the basis of already validated questions for background variables and media use patterns. For value variables we used Hofstede's cultural values scale, applied to individual differences [7]. We designed the questions about technologies, functionalities and modes of governance ourselves, but we constructed them as sets of multiple statements so that scale construction would be possible, enhancing the validity of the combined measurement instruments. We added, were possible, visual representations of the technologies we asked about, in combination with a short written explanation of what they would entail. We collected the data in the spring of 2013, and stopped data collection after reaching a total number of 1000 respondents who were representative for the UK population in terms of gender (a roughly 50-50 division of women and men), age (median age around 40), household size (about 2.4). In terms of ethnicity and education the sample turned out to be biased slightly towards white people and seriously towards higher educated people.

Our strategy for data analysis was explorative, as the lack of studies about structural taboos and desires for identity management in which experience and affect are highlighted rather than (the perception of) efficiency and cognition, did not allow for the development of specific and precise hypothesis. This meant that we conducted a number of bivariate and multivariate associational and correlational analyses, and combined those with clustering techniques.

\section{RESULTS}

\subsection{Current means and problems of I\&A}

Passport, driving license and bank cards for offline I\&A, and pincodes and passwords for online I\&A, are all used by more than three quarters of our sample. Secondary means of I\&A, mentioned by about a quarter of the sample concern loyalty cards, birth certificate and other civil register information, and tax or utility bills. On average, people have about 17 different means of I\&A at their disposal, mostly token or memory based. Biometrics have not entered everyday life in the UK yet. About a third of the respondents have experienced one type of biometric measure, typically a body scan at the airport. People don't seem to have many problems handling their means if I\&A; half of the respondents reported minor issues such as losing cards, misplacing them or getting them damaged. Only about five percent of the respondents said they had experienced serious card theft (of money or their identity). A similarly unproblematic picture emerges from people's management of their passwords and pincodes; people claim to have no problems remembering them and only a few respondents indicate that they have to look them up again and again, or keep them externally (written down offline or online). The usage of an online password management service is rare.

We found that identity management is strongly stratified, meaning that socio-economically vulnerable groups who spent less time in education have fewer means of identification than strong socio- economic groups with a longer education history. Other standard demographic variables like age, gender, household size or ethnicity do not make a difference.

\subsection{Future technologies of I\&A}

In the first TESSA Game, the respondents were shown four pictures of future technologies of I\&A. Through a 'hover-andlearn' function, it was explained what people saw in the picture and how it worked as an ID instrument. (See Figure 1 for the four futuristic technologies that were asked about).

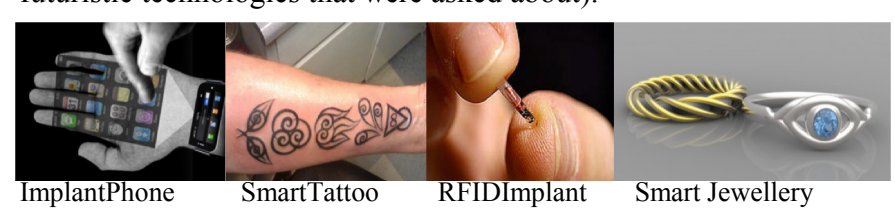

Figure 1. Futuristic I\&A stimuli

We asked whether our respondents liked or disliked these, and how big the chance was that they ever would use one of them. We also asked them to comment on each item. By and large the respondents did not like any of these four options and did not seem inclined to use them. The smart jewel was the most popular, but still only among a third of the respondents, and few people said they would think of using it. The smart tattoo was the least popular with only $13.5 \%$ of the respondents saying they liked it, and even less considering adopting it in the future. It evoked strong associations with the prisoner number the Nazis tattooed on Jewish and other inmates of the concentration camps. In addition, respondents saw tattoos as being tasteless, calling them tramp-stamps, chavvy, tacky and the like. In addition, they found it too visible, and therewith easily subject to fraud. Nevertheless, people do expect these technologies to be part of our future. In fact, two third of our respondents expects that the (implanted) smart phone will further evolve, as will the RFID Implant and the smart jewel. There is no majority expectation for further evolvement of for the smart tattoo however.

There were significant differences between groups: younger age groups, non-white respondents and people without university education were less negative about these innovations, and were less unlikely to say they would use them. Of the different media use variables we tested, only heavy mobile phone usage and heavy magazine reading enhanced the possibility of respondents liking and using the innovations. People with a high trust in state agencies (police, legal system, secret service) or a high trust in politics (politicians, parties, parliament) also expressed more appreciation for these innovations and thought it more likely that they would use them. Finally, in terms of cultural values, an egalitarian, individualistic and emancipated orientation contributes to the acceptance of these innovations. It is, nevertheless, important to notice that these differences refer basically to lower degrees of dislike and non-usage, rather than to having a strong appreciation and desires to use the new technologies [all bivariate tests conducted by comparing means (ANOVA) or Pearson's correlation coefficients, $\mathrm{p}<.001$ ).

In the second game, DUBIOUS, where we asked people to imagine they were living in the future, this pattern of dislikes was confirmed. In dressing the future avatar, again the smart tattoo was the least popular choice, followed by the two implants (phone and chip) and the smart jewel. Instruments that were closer to current gadgets, however, were chosen for the avatar: $56.3 \%$ of the respondents dressed their avatar with an 'AccessAllServices Watch', and about $40 \%$ with digital contact lenses, Google Glasses or GPS footwear. 


\subsection{Future functionalities of $I \& A$}

We presented the respondents with a list of 15 items about possible innovations in means of identity management. The items were primarily based on the outcomes of our scenario analysis. Respondents could answer 'yes', 'no' or 'not sure'. In the table below these items are ranked according to their popularity in the sample. The table gives the percentage of people who clicked 'yes' when prompted for their response to that particular item.

Table 1. Future functionalities

\section{I wish that in the future ..... $\%$}

\begin{tabular}{|l|c|}
\hline I could have all my medical information on one card & 70.3 \\
\hline I could read my own cards so that I knew where and & 61.8 \\
\hline
\end{tabular}

when I used them

I could have a tracker on each of my cards so that I could never lose them

\begin{tabular}{|l|l|}
\hline I could have one card with which I could do everything & 42.5 \\
\hline
\end{tabular}

\begin{tabular}{|l|l|} 
my kids would have a card with a tracker on it so that I & 37.9
\end{tabular}

could monitor where they are

\begin{tabular}{|l|c|}
\hline I like to have many different cards for different purposes & 37.2 \\
\hline $\begin{array}{l}\text { credits on one customer card would add to those on the } \\
\text { others }\end{array}$ & 36.2 \\
\hline
\end{tabular}

\begin{tabular}{|l|l}
\hline my cards would start beeping if there was a criminal & 34.0
\end{tabular}

nearby

we could get rid of cards altogether and replace them

with a fingerprint or other biometric

\begin{tabular}{l|l} 
I could 'pimp' my credit and customer cards so that they & 28.8
\end{tabular}

look more personal

\begin{tabular}{|l|l|}
\hline my membership card would tell me that there are other & 16.1
\end{tabular}

members nearby

we could get rid of cards altogether and replace them

with a body implant that contains the same information

we could get rid of cards altogether and replace them

with apps on our smart phones

we could get rid of cards altogether and use smart

jewellery or textiles instead

my customer card would tell me if there are other people

in the store who have the same taste and preference as I have

Table 1 shows that more than half of our respondents see clear possibilities for improvements of their current cards which would offer more ease and transparency of use (items 1,2,3); the two possible safety options on cards (to track one's kids and warn against criminals) draw about a third of the respondents; the 'social options' for membership and customer cards are not very popular; neither are the suggestion to replace cards with one other I\&A instrument (a biometric, app, implant or jewel). The latter low popularity connects well to the outcomes about new kinds of I\&A technologies reported in the previous paragraph.

In order to explore the possible relations between these desires and differences among respondents according to socio- demographic, media use patterns and cultural values, we performed a forward stepwise regression (with the dependent variable transformed into a dummy variable, with the 'not-sure' answers treated as missing). We set a strict significance level with the boundary for entry being $p=.01$. While none of the resulting models explained much variance, they do give an indication how the various desires for new functionalities in I\&A are divided across groups with different socio-economic features, media use patterns and cultural values. We summarize them in Table 2 below.

Table 2. Distribution of desires among different groups

\begin{tabular}{|l|l|}
\hline Desires for & More often among \\
\hline Medical card & $\begin{array}{l}\text { People on lower incomes, and those } \\
\text { oriented to group interests }\end{array}$ \\
\hline Readable card & People with less education \\
\hline Trackable card & $\begin{array}{l}\text { Women, those with less education, and } \\
\text { those living in a bigger household }\end{array}$ \\
\hline $\begin{array}{l}\text { Kidstracker card card for } \\
\text { everything }\end{array}$ & $\begin{array}{l}\text { Women with less education, and those } \\
\text { oriented to group interests }\end{array}$ \\
\hline $\begin{array}{l}\text { One biometric } \\
\text { Social customer } \\
\text { card }\end{array}$ & $\begin{array}{l}\text { Women, those on a lower income, those } \\
\text { with high trust in the state } \\
\text { magazine fans, slightly hierarchical and } \\
\text { oriented to long term goals }\end{array}$ \\
\hline $\begin{array}{l}\text { Smart apps on } \\
\text { mobile }\end{array}$ & $\begin{array}{l}\text { Younger people, those sensitive for clear } \\
\text { instructions and to hierarchy. }\end{array}$ \\
\hline One body implant & Men, those sensitive to hierarchy \\
\hline Total Customer card & People of colour \\
\hline $\begin{array}{l}\text { Social membership } \\
\text { card }\end{array}$ & $\begin{array}{l}\text { Women; low internet usage; low } \\
\text { newspaper readership; high on hierarchy; } \\
\text { high on group interests }\end{array}$ \\
\hline $\begin{array}{l}\text { Smart jewellery or } \\
\text { textile }\end{array}$ & $\begin{array}{l}\text { Women; magazine readers } \\
\text { Criminal alert card } \\
\text { education; newspaper reader }\end{array}$ \\
\hline
\end{tabular}

Many of these outcomes make intuitive sense: the desire for one medical card increases with age; people who have difficulty coping with their present income would like to check their expenses by being able to read their own cards; women living in bigger households welcome the opportunity to keep track of their kids; women who love reading magazines are more interested in smart ID jewellery or textile; and so on.

We explored, in addition, whether there were specific items that people implicitly clustered together as belonging to the same set of desires. This was only the case for the items that expressed a wish to get rid of cards altogether and replace them with one biometric, a body implant, phone apps, or smart jewellery (alpha $=.62$ ). This desire is, however, not very frequently present in our sample: only $18.1 \%$ opted for one or more of these statements. These were more often men with a stronger appreciation of hierarchy than other respondents (similarly tested with stepwise regression). 


\subsection{Future governance of $I \& A$}

We offered respondents 25 statements about future developments

in the governance of I\&A; they could indicate on a scale of 4 (high) to 1 (low) whether they thought this was a likely development for the future or not. Some of these statements were expressed as a clear desire, others as a taboo, and in some statements the desirability of the item was expressed by the answer categories ('e.g. sorry to disappoint, that is not gonna happen). The statements thus represent not so much what they want, but whether they see their fears or desires come through in the future. In table 3 the rank order of these statements are given:

Table 3. Which taboos or desires for governance will come through?

\begin{tabular}{|l|c|}
\hline $\begin{array}{l}\text { Item } \\
\text { almost }\end{array}$ \\
\hline $\begin{array}{l}\text { 1. I think it is vital that the police force expands its } \\
\text { separate and specialized cybercrime units. Will that } \\
\text { happen? }\end{array}$ & 86.6 \\
\hline $\begin{array}{l}\text { 2. I expect that in the future, most workplaces will } \\
\text { have monitoring software and other mechanisms to } \\
\text { assess the individual productivity of employees. }\end{array}$ & 86.0 \\
\hline $\begin{array}{l}\text { 3. I'm afraid that in the future, the government will be } \\
\text { able to connect different data about me, such as my } \\
\text { bank accounts, work history, private possessions and } \\
\text { tax data. Are they able to do that in 2030? }\end{array}$ & 85.7 \\
\hline $\begin{array}{l}\text { 4. There will still be free services on the internet in the } \\
\text { future, but I reckon we'll be subjected to lots of } \\
\text { adverts. }\end{array}$ & 84.4 \\
\hline $\begin{array}{l}\text { 5. I hope that in the future I can find out what } \\
\text { information about me is online, and in which } \\
\text { databases. Will I get my wish? }\end{array}$ & 82.2 \\
\hline $\begin{array}{l}\text { 6. I hear that the government has developed more } \\
\text { spying software that is almost watertight in tracing } \\
\text { criminal and terrorist scheming online. }\end{array}$ & 82.2 \\
\hline $\begin{array}{l}\text { 7. I read somewhere that in the future each company } \\
\text { handling personal data will need to have a Data } \\
\text { Protection Officer who can be held responsible for } \\
\text { breaches of privacy. Has that happened? }\end{array}$ & 74.0 \\
\hline $\begin{array}{l}\text { 8. I heard that in the future everybody will have one } \\
\text { secure digital signature that gives them immediate } \\
\text { access to all online services and stores so that they } \\
\text { don't have to remember usernames and passwords } \\
\text { anymore. }\end{array}$ & 72.0 \\
\hline $\begin{array}{l}\text { 9. Is it true that Facebook will offer bespoke } \\
\text { competence profiles of individual users, based on their } \\
\text { social network activities, to employers looking for } \\
\text { specific personnel? }\end{array}$ & \\
\hline $\begin{array}{l}\text { 10. I expect that the systems I use will be self- } \\
\text { learning, meaning that after a while they know what to } \\
\text { do themselves. My television, for instance, will just go } \\
\text { to the right channel when I want to watch one of my } \\
\text { favorites }\end{array}$ & \\
\hline
\end{tabular}

11. I would be so glad if the future offered implants that could monitor our health and warn us in time to get treatment.

12. The way things are going, we're going to have to pay to retain any privacy on the internet in the future

13. I can't help thinking that in the future we'll get discounts for everything we buy, provided we have the right mobile or social network account.

14. I'm not even sure who owns the stuff I put on Facebook now, let alone in the future. If I want to make sure it's me, will I have to pay for that?

15. If they let you delete your data and profiles from the internet in the future, it'll definitely cost money, won't it?

16. I wish that in the future I could have an online identity that can only be traced to my offline identity if I consent to it.

17. Is it true that in the future you can send your children to a school that allows you to watch what they're doing through cameras in class?

18. I hope that it becomes illegal to offer social network possibilities to children under 12

19. I think it would be good if in the future we can check the financial records of our representatives, like MPs or the Prime Minister, or a union leader. Is that possible?

20. I would love it if all authentications became invisible, through systems of remote biometrics. A smart phone that recognizes you on the basis of how you walk, for instance, or a laptop that recognizes the way you type.

21. I hope that the governments of the world have been able to make it illegal for companies to sell personal data for marketing purposes.

22. In the future, will I be able to delete stuff like my Facebook and Twitter history so that I can completely remove my online existence?

23. I am afraid that identity theft will be a major problem in the future, or is it under control?

24. I've heard that in the future, ordinary people can access any CCTV camera through the internet, whenever they want too. Is that true?

25. People say that after Wikileaks, all international government and diplomatic communication will be open to the public. Has that happened in your time?

Given that the survey was online when the information about the US and UK governments systematically tracking their citizens' online trails reached the news, it is probably not surprising that the surveillance items rank high, and that our respondents are not very happy with those future prospects. Our respondents are much less convinced that more desirable future developments including transparency and accountability are likely to occur: only about half of the people think identity theft will be under control, or that they will be able to delete their online presence. 
We then subjected all items to principal component analysis to determine underlying structures. With five factors about half of the variance in the data was explained $(49.6 \%)$. The strongest factor, explaining $20.2 \%$ of the data covered desires about online identity control as expressed in the items 21,22 , 18 and 16). Looking back at table 3, it shows that these represent future ideals that about half of the people see occurring. The second clear factor (explaining $14.8 \%$ ) concerns commercial development as expressed in items 14,12 and 22 . Here too, we see that many people are convinced that the future of I\&A will be subject to commercial imperatives. The next three factors each pick up about $5 \%$ of the variance and represent the desire for I\&A to make life easier (items 8, 10,20 and 11), something that people tend to find likely to happen in the future; $h$ concerns and desires about surveillance (items 1, 2, 3 and 6) and surveillance is strongly expected for the future. Finally there is a watching-the-watchers factor that is expressed in items 24, 17 and 19, and that people think unlikely to occur. These tendencies are summarized in table 4 .

Table 4. Which taboos or desires for governance will come through - summary

\begin{tabular}{|l|l|l|l|}
\hline \multicolumn{3}{|c}{ Will happen } & Mixed \\
\hline Desire & $\begin{array}{l}\text { Make life } \\
\text { easier }\end{array}$ & $\begin{array}{l}\text { Personal } \\
\text { identity control }\end{array}$ \\
\hline Taboo & Commercial & & \\
\hline Mixed & Surveillance & & Watching back \\
\hline
\end{tabular}

To explore the differences between our respondents, we conducted a forward stepwise regression with the factor scores as dependent variables. We set strict significance level with the boundary for entry being $\mathrm{p}=.01$. The resulting models explained little variance, but we take them as suggesting tendencies about how the various expectations about future governance of I\&A are divided across groups with different socio-economic features, media use patterns and cultural values.

The respondents who want a degree of control over their online identities ànd think this is likely to be possible in the future, tend to be more often women, who trust state agencies, have a stronger sense of hierarchy than others, are oriented towards long term goals and say they don't value clear instructions very much.

We find respondents who fear commercial developments around I\&A, but think these will occur anyway more often among older people, who are heavy radio listeners. Remember, however, that this is a widespread fear that is not unique to this group.

The people who want and expect I\&A to make life easier in the future tend to be more often men who find group spirit more important than individual benefit.

The mixed vision of a surveillance future is partly dependent on cultural values (not very interested in long term goals, egalitarian, oriented towards group), and is more often found among young white respondents who don't read newspapers. Remember here too, that this factor represents items that are shared by more than $80 \%$ of the respondents.

Finally, the relatively few people who think watching-thewatchers will be possible in the future tend to have a stronger sense of hierarchy than other respondents, and have had less education.

\section{SUMMARY, DISCUSSION AND RECOMMENDATIONS}

\subsection{Summary}

The two research games we conducted were meant to provide information about current means of I\&A used by (different segments of) the UK public, and their desires and taboos about future means, functionalities and governance of I\&A. With respect to current usage of I\&A, we found that standard, token based and memory based means of I\&A dominate among the UK public; exposure to biometrics is not frequent and mostly related to air travel. Few people report having serious problems with their current deployment of token and memory bsaed I\&A means. Current usage of I\&A is socially stratified: socio-economically vulnerable groups who spent less time in education have fewer means of I\&A than strong socio- economic groups with a longer education history.

Respondents express strong taboos for new futuristic means of I\&A that occur regularly in future scenarios from the industry, arts and design, pop culture and journalism, especially tattoos and body implants. The data suggest also, however, that the innovations that are closer to what is currently known, like smart watches or Google Glasses, are more acceptable.

Respondents express more enthusiasm for enhanced functionalities of their current means of I\&A, and can imagine all kinds of desirable new features that would make their current set of I\&A cards more efficient and usable. Options where cards are replaced with other means of I\&A (like smart phone apps or biometrics) are very unpopular in our sample.

In terms of the governance of their I\&A there is a strong desire and expectation to have personalized, tailor made services of I\&A in the future. Respondents also expressed clear desires for possibilities to control one's own online identity, but have less faith that this will happen in the future. People do not want to have commercialized forms of I\&A, and express mixed feelings about increased surveillance; both, however, are expected to become stronger in the future. A possibility to watch-thewatchers, regardless of its desirability, is not expected to happen.

The analysis of individual differences between respondents on all of the above issues, hardly showed a clear direction; standard background variables matter for some questions, but not for others. Media use patterns are related to some patterns but not to others, as are trust and cultural values. The results thus demonstrate that desires and taboos for specific means, functionalities and governance of I\&M in the future are entirely situational; dependent on specific people, in specific circumstances with specific ideas and values.

\subsection{Discussion}

The research presented is the first in its kind and is, hence, subject to a number of 'novelty' challenges:

It focused on desires and taboos, rather than of efficiency and added value as in other research about the acceptance of I\&A, or of new technologies in general. Questions that specifically tap into such feelings have hardly been developed and as a result our questionnaire was innovative but tentative. We tried to preempt issues of question validity by presenting various items to our respondents that were meant to tap into the same problematic (see especially Tables 1 and 3). However, in the absence of 
standardized measurement instruments, our results need to be taken as indicative rather than as definitive;

It focused on the future instead of on the present, on things and issues people don't know yet. We thus asked a considerable effort from people to imagine the future, and imported another set of uncertainties about the validity of questions and the meaning of answers. For some questions, respondents could add some of their considerations which gave us more insight into how they perceived a particular innovation. In other cases that was not possible, and as a result it remains a bit unclear, for instance, what people imagine a statement about citizens accessing CCTV cameras to mean. This, again, means that we need to look at the results as tendencies instead of watertight results;

Finally, we offered the questions to our respondents in the form of two research games, one inviting the respondent to take the role of a spy, the other asking him or her to imagine living in the future. This moves the study out of the comfort zone of the well exercised requirements for good survey design like question wording, question order, or scale construction. To all these, colour, images and sounds are added and we have little clue whether and how this affects answer patterns. In addition, it is not by definition clear who the respondents pretends to be when answering the questions: does s/he answer as herself or as an imagined spy or futuristic avatar?

Notwithstanding these challenges, we think the results are useful; partly because they are in line with expectations, as for instance with the social stratification of current I\&A, and the greater acceptability of already familiar gadgets; partly because they make intuitive sense as with female magazine readers expressing desire for smart jewellery or older people being more interested in a medical card. Where the results are less clear, for instance when it comes to the role of cultural values for desires and taboos around future I\&A, they can be taken as warning signs for future research and practice not to ignore these variables. They do play an important role, although we can't exactly predict how.

\subsection{Recommendations}

We hope that our research outcomes will lead to new hypothesis and research instruments to further tap into the future of I\&A. We feel that in particular the relation between individual differences and specific desires and taboos can be analysed and tested in more detail. In addition, we think that our aim to take stock of taboos and desires that run across technologies has overlooked the growing significance of smart phones for I\&A, although few of our respondents indicated that they currently consider their phone a means for that purpose. However, given the particular diffusion curve of the smart phone and its apps, a more in depth analysis of its relevance of an I\&A instrument of the future is needed.

How can our outcomes be made practical for designers and developers of I\&A system, especially with respect to the means, functionalities and governance that possible users require.

With respect to means and functionalities the data make clear that there is no one-size-fits all solution. While a biometric measure may be easy and relatively cheap from the perspective of the I\&A provider, it is not a very desired means for users, nor is it one that people have easy experience or happy associations with. Given the current satisfaction with cards and the desires for enhanced functionalities, a card for I\&A purposes seems the safest and least controversial option, possibly with varying degrees of information on it. Yet, if one's target group or community has specific futures, for instance, young, smart phone dependent and happy to receive instructions, a smart I\&A app could be recommendable. In the case of ample resources, tailor made I\&A through the means of one's choice should be made possible as this is also what people hope will happen in the future.

With respect to the governance of I\&A it is striking that people do want control over their personal online information but fear that it is not going to happen in the future, or that it will cost them money. Any system that would offer such transparency to its users at little or no costs, is bound to score more points with them than other ones.

\section{ACKNOWLEDGMENTS}

We are indebted to the Engineering and Physical Sciences Research Council (EPSRC) of the UK for their generous support for this research, EP/J005037/1.

See for more information about the project: www.imprintsfutures.org

\section{REFERENCES}

[1] Akrich, M. (1995). User Representations: Practices, Methods and Sociology.Managing Technology in Society. The Approach of Constructive Technology Assessment, 167-184.

[2] Venkatesh, V., \& Davis, F. D. (2000). A theoretical extension of the technology acceptance model: four longitudinal field studies. Management science, 46(2), 186-204.

[3] Hornbæk, K. (2006). Current practice in measuring usability: Challenges to usability studies and research. International journal of human-computer studies,64(2), 79-102.

[4] Van Zoonen, L. et al., (2012). Scenarios of identity management in the future. Available at: http://www.imprintsfutures.org/assets/images/pdfs/Scenarios of_identity_management_in_the_future_Report.pdf

[5] MacVaugh, J., \& Schiavone, F. (2010). Limits to the diffusion of innovation: A literature review and integrative model. European Journal of Innovation Management, 13(2), 197-221.

[6] Turner, G., Van Zoonen, L. \& B. Adamou (forthcoming). Research through gaming: public perceptions of (the future of) identity management. Prepared and accepted for the Sage Online Series Research Methods in the Social Sciences. Available at request with the authors.

[7] Yoo, B., Donthu, N. \& T. Lenartowicz (2011): Measuring Hofstede's Five Dimensions of Cultural Values at the Individual Level: Development and Validation of CVSCALE, Journal of International Consumer Marketing, 23:3-4, 193210 . 